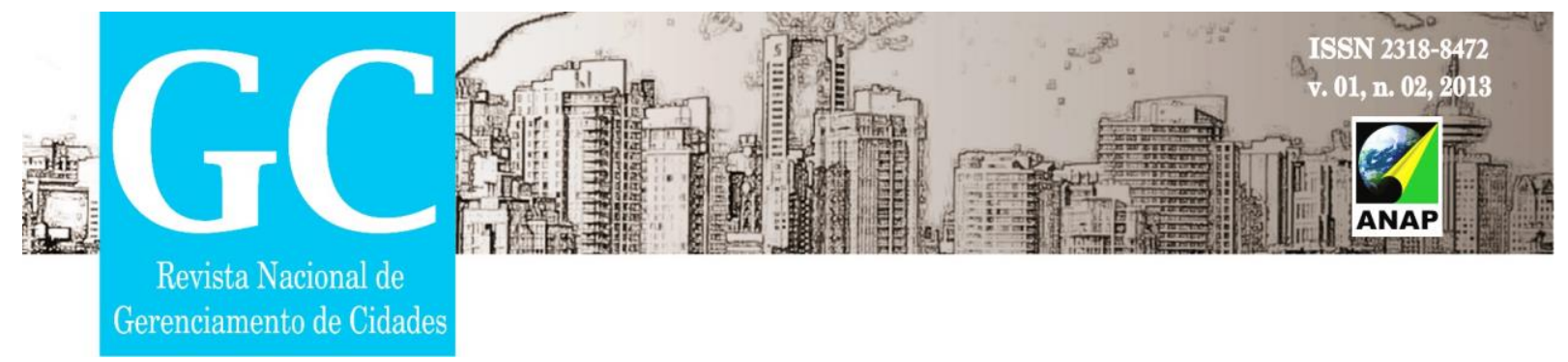

\title{
CARACTERÍSTICAS E ORGANIZAÇÃO ESPACIAL DO MUNICÍPIO DE ALTO ALEGRE/RR
}

\author{
Felipe Melo de Souza ${ }^{1}$
}

\section{Antônio Tolrino de Resende Veras ${ }^{2}$}

RESUMO: O artigo intitulado característica e organização espacial do Município de Alto Alegre, localizado no Estado de Roraima têm como objetivo apresentar algumas considerações relacionadas à percepção visual a partir de uma analise feita através de visita na cidade, apresentado seus pontos importantes na percepção urbana e sua relação com o discurso de alguns autores apresentados no presente artigo, fazendo uma reflexão na produção do espaço do município a partir de seu traçado urbano e de sua flexibilidade junto com seus habitantes.

Arquiteto e Urbanista, UFRR, mestrando em geografia do PPG - GEO/UFRR; felipesouza@dau.ufrr.br

2 Doutor em Geografia, UFRR, professor do PPG - GEO/UFRR; tolrino@usp.br 


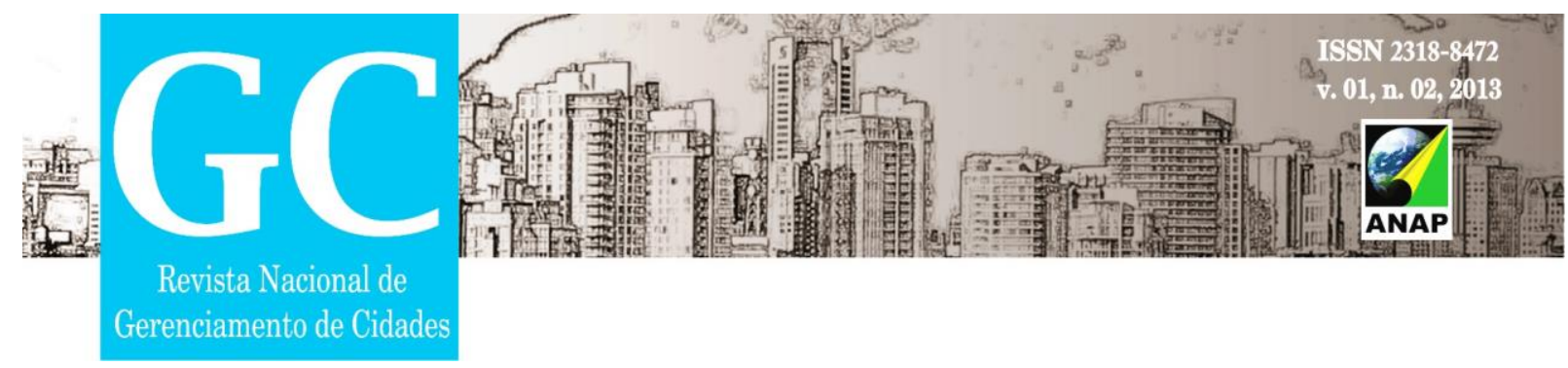

\section{INTRODUÇÃO}

O espaço deve ser estudado por meio de quatro categorias: forma é o 'aspecto visível de uma coisa', 'o arranjo ordenado de objetos', um padrão; função 'sugere uma tarefa inesperada de uma forma, pessoa, instituição ou coisa' estrutura 'implica a inter - relação de todas as partes de um todo, o modo de construção' e processo, que 'pode ser definido como uma ação contínua, desenvolvendo-se em direção a um resultado qualquer, implicando conceitos de tempo (continuidade) e mudança' (SANTOS APUD SPOSITO, 2004)

Um primeiro olhar sobre o município de Alto Alegre, localizado no Estado de Roraima, tem-se um município bem organizado através de seu projeto urbanístico, com a grande maioria das quadras dos loteamentos no formato "quadrado", sendo a avenida $1^{\circ}$ de julho a principal avenida do município, entrada principal, sendo todas as avenidas laterais perpendiculares. Uma das características encontradas é o grande números de árvores do tipo "oiti" distribuídos entre as ruas e avenidas, produzindo grandes áreas de sombra, criando um conforto bioclimático no município. 


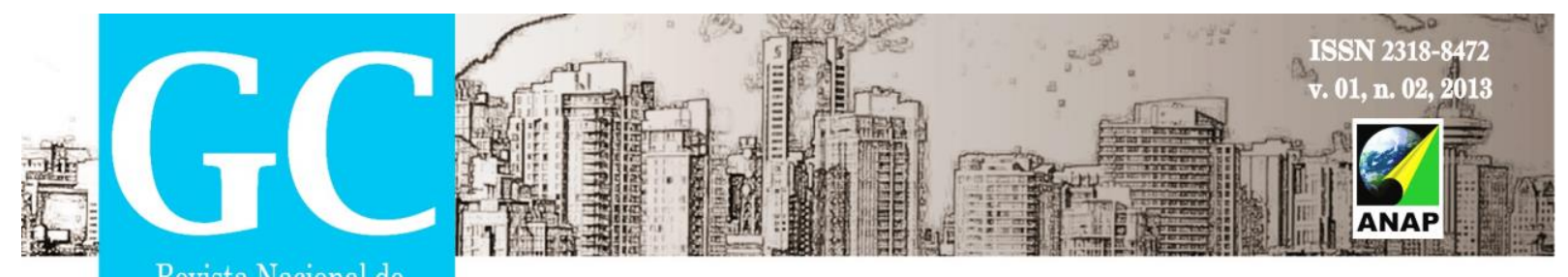

Revista Nacional de

Gerenciamento de Cidades

Figura 01: Traçado Urbanístico Principal da cidade de Alto Alegre

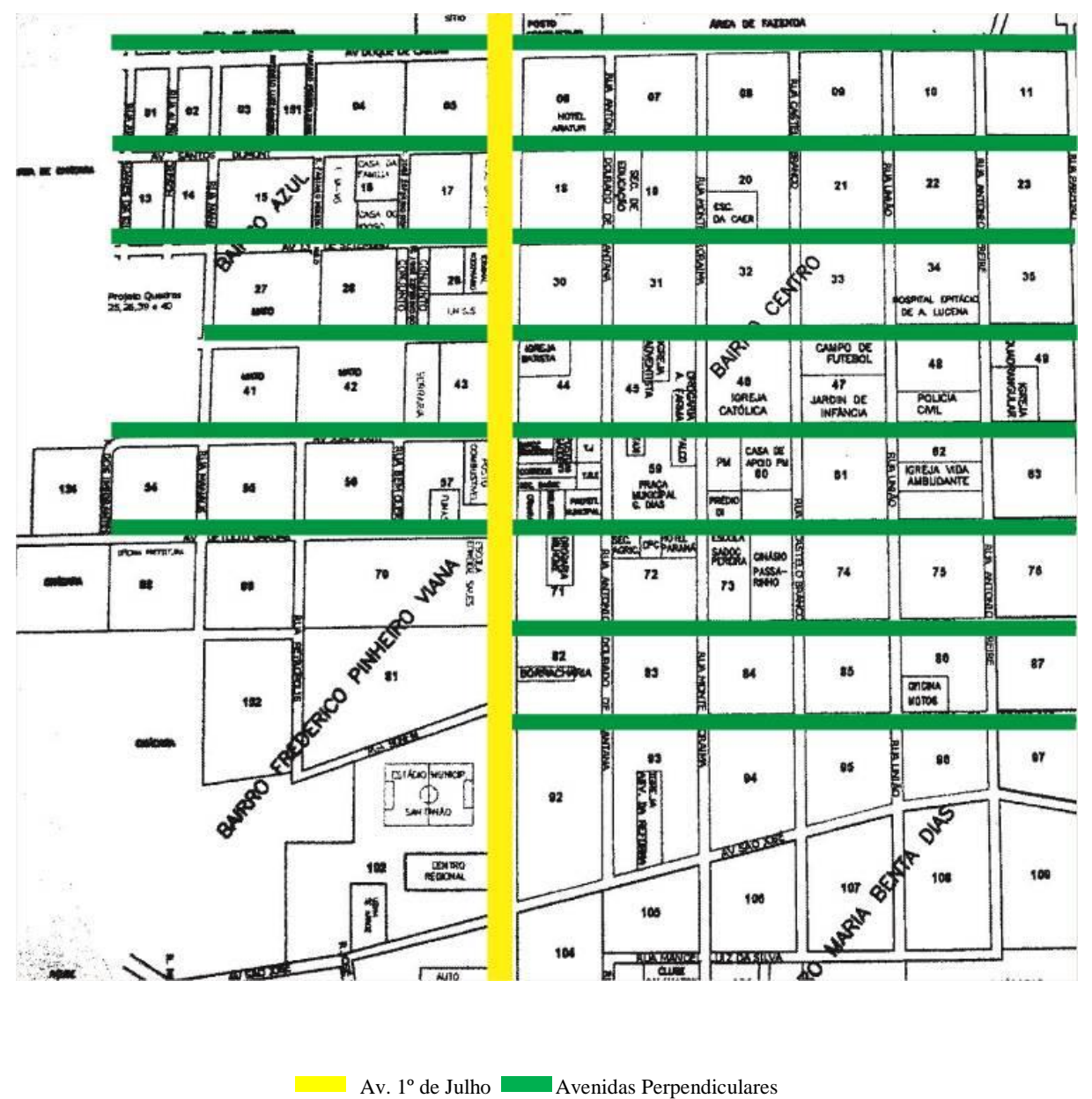

Fonte: SOUZA, Felipe Melo, 2013

A partir desse desenho podemos dialogar sobre a produção desse espaço com Edgar Morin que afirma que:

Assim a ordem, desordem, organização se co-produziram simultaneamente e reciprocamente.sob efeitos de encontros aleatórios, as imposições originais produziram as inter-relações organizacionais. Há então um circuito de co-produção mútua: ordem - desordem - interações - organizações. (MORIN, 2003, p. 76) 


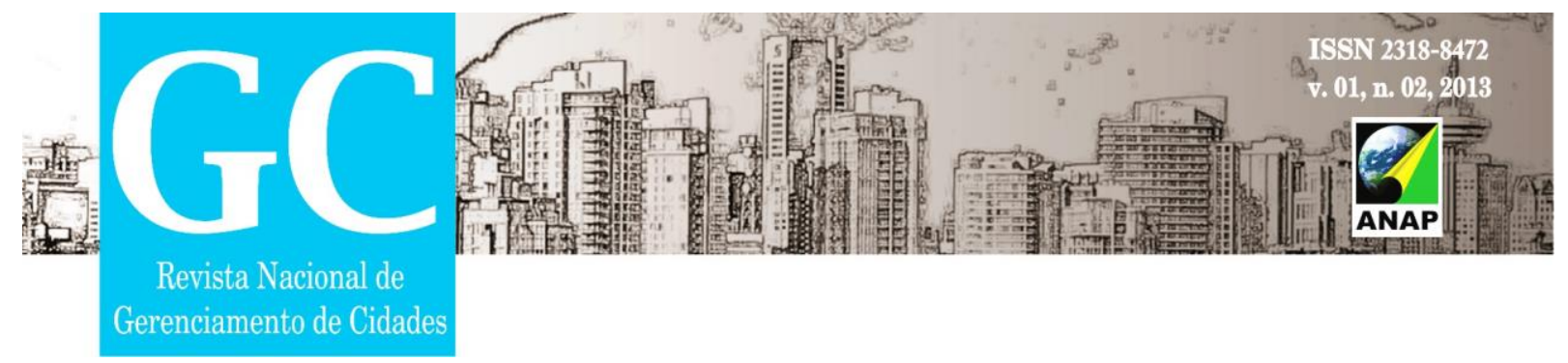

O formato urbanístico da cidade nos traz uma organização que dialoga muito bem com MORIN, no sentido de percepção, em que todas as avenidas tem as mesmas dimensões, o que acaba criando uma ordem e também uma semelhança de características presentes nas referidas avenidas criando uma ordem geral, e que muitas vezes as avenidas se confundem em virtude dessa semelhança. A apartir disso a desordem aparece como uma alternativa para amenizar essa condição de semelhança através de alterações pontuais na característica individual de algumas edificações, que podemos perceber como forma de romper com essa ordem criando uma interação com o conjunto como todo, essas alterações dialogam através das cores e formas presentes nas casas, fazendo um contraste entre e novo e velho.

\section{AVENIDA 1ํㅡㄹ JULHO}

Temos a avenida $1^{\circ}$ de julho como a principal avenida do município, porta de entrada, ligando o município às demais regiões, possui uma importância, pois nela estão os principais comércios e serviços. Ao analisarmos a sua estrutura, temos uma área de grande valor urbano, mas que ainda possui problemas relacionados as dimensões dos logradouros e a testada principal da fachada dos edifícios, que em alguns casos avança consideravelmente no logradouro. Ao percorremos a avenida percebemos grandes vazios urbanos, além de muitas habitações residenciais históricas em alguns pontos da avenida, além de importantes órgãos públicos como a feira do município, rodoviária, companhia de eletricidade (CER), edifício do INSS, escolas públicas, estádio de futebol, entre outros.

Os lugares para onde estas vias convergem levam vantagem em relação aos outros: nesses lugares fica mais fácil organizar encontros, estabelecer relações e fechar negócios [...] as cidades são comutadores sociais, formas de organizações do espaço destinadas a facilitar ao máximo toDas as formas de interação. (MENDONÇA E COZEL, p. 18) 


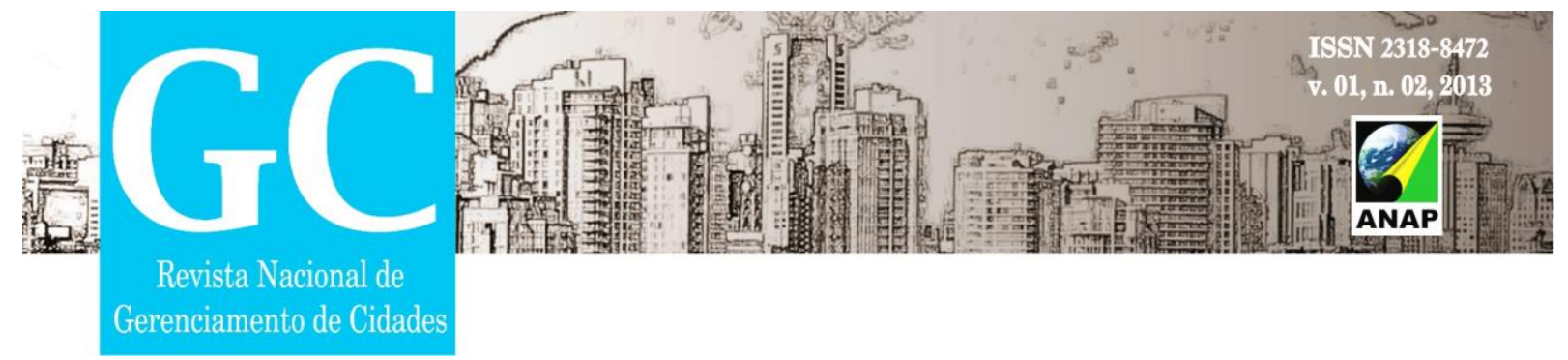

A avenida $1^{\circ}$ de julho tem essa característica, concentra aproximadamente 90\% do comércio e serviços locais em detrimento as outras áreas da cidade que são pontuais ao longo das avenidas criando uma dispersão espacial, deixando a cidade dispersa em relação ao comércio e serviço, uma outra característica que se pode notar em relação a avenida $1^{\circ}$ de julho e que ela é ponto de ligação de entrada e saída da cidade de Alto Alegre, além de ser elo de ligação entre as demais áreas de Alto Alegre, que inclui suas comunidades indígenas e demais áreas de assentamento.

Uma outra característica presente na cidade de Alto Alegre é a relação entre sagrado e profano que é visível na organização e definido através das grandes áreas destinadas as suas atividades distribuídas entre suas mais diversas ordens religiosas, sendo reforçado por Mendonça e Kozel apud Eliade, 1965:

A posição entre sagrado e profano fundamenta-se na ideia de que existem dois níveis de realidades: o mundo positivo, apreendido pelos nossos sentidos, que tocamos, que frequentamos, e um outro mundo, onde se situam as forças, os princípios ou as divindades que são responsáveis pelo que acontece no mundo positivo

Figura 03: Avanços das testada de edificações

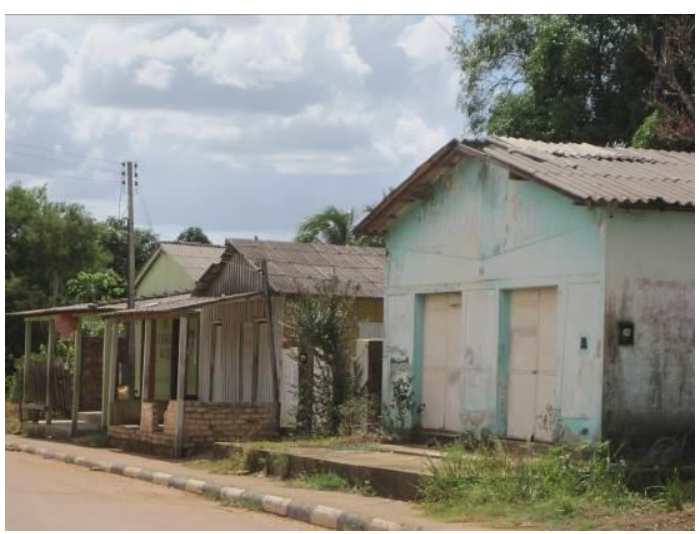

Fonte: SOUZA, Felipe Melo, 2013
Figura 04: Diferenças de testadas de

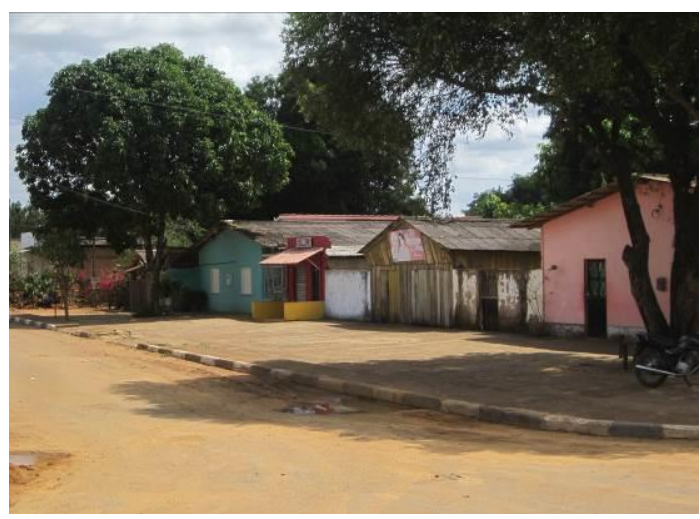

Fonte: SOUZA, Felipe Melo, 2013 


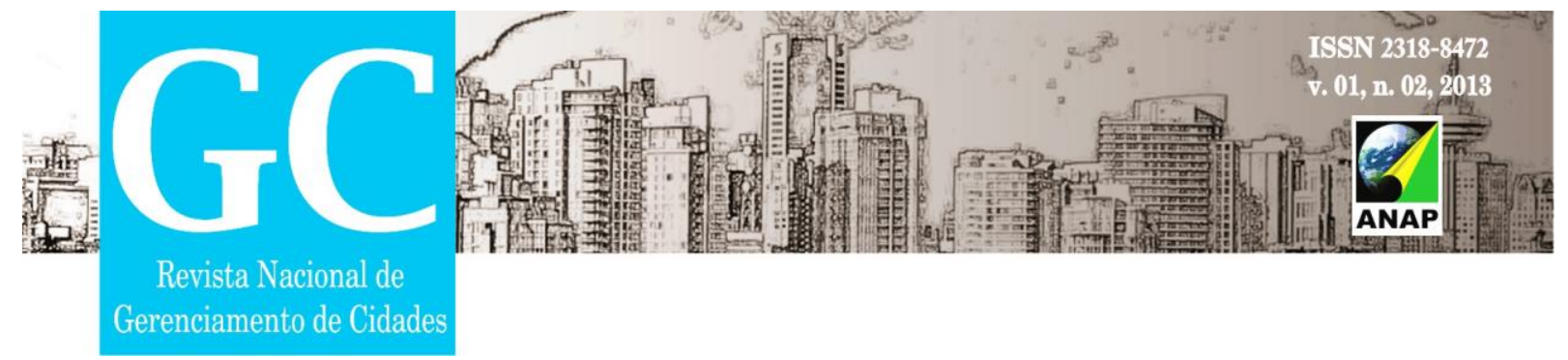

No bairro centro temos uma grande concentração de setores públicos, como Prefeitura Municipal, praça, fórum, posto de saúde, bem como igrejas das mais diferentes denominações. Observa-se com essa distribuição de órgãos e setores públicos, uma grande valorização da área urbana, o que induz a uma futura exploração imobiliária.

Figura 05: Cobertura localizada na Praça G. Dias

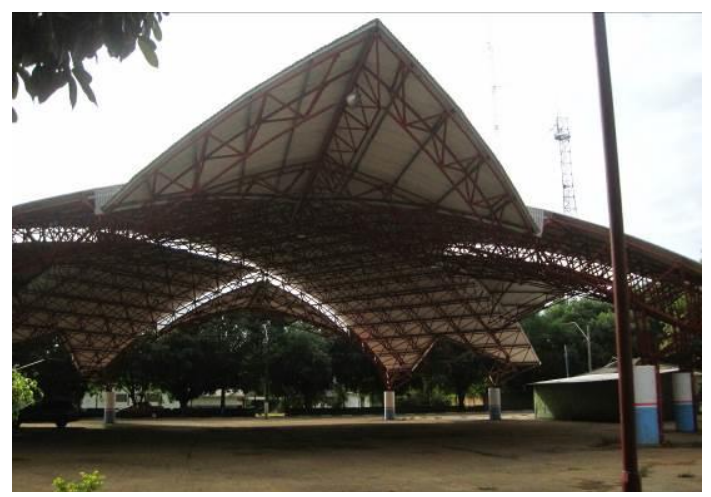

Fonte: SOUZA, Felipe Melo, 2013
Figura 06: Nova sede INSS

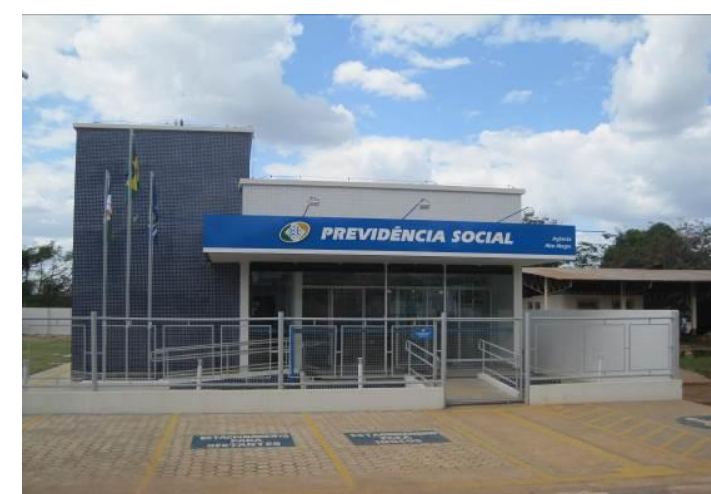

Fonte: SOUZA, Felipe Melo, 2013

O município do Alto Alegre possui algumas áreas de interesse para a expansão urbana, sendo o bairro azul, onde se localizam as chácaras e que hoje já sofre modificações em virtude da transformação da área rural em urbana, ficando o poder público responsável pelas obras de infraestrutura para atrair e valorizar a referida área, induzindo a ocupação por parte dos moradores. 


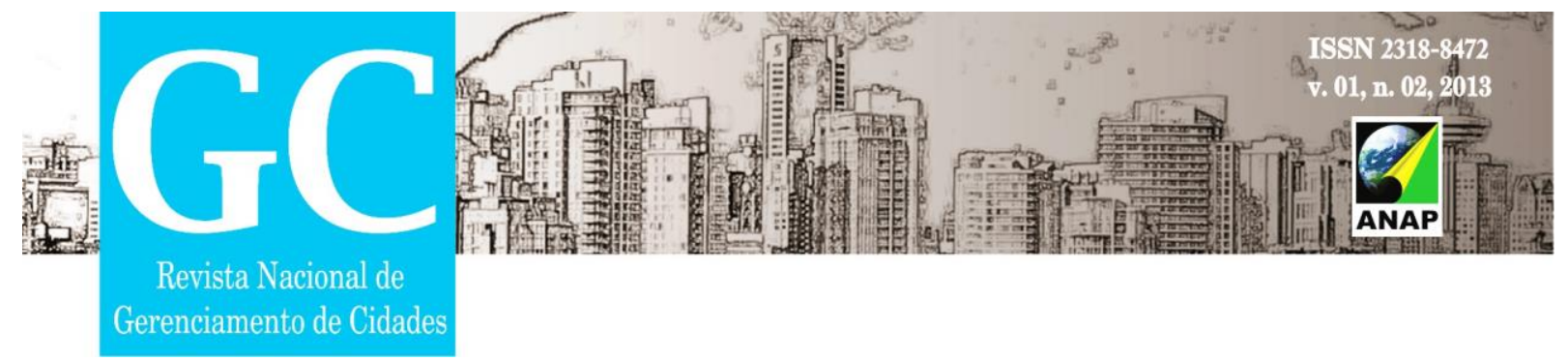

Figura 07: Rua Zeferino Gomes sem infraestrutura

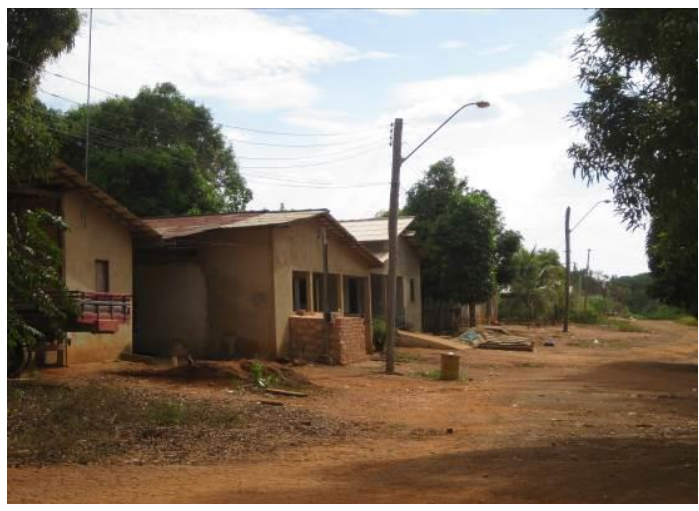

Fonte: SOUZA, Felipe Melo, 2013
Figura 08: Edificações existentes no bairro azul

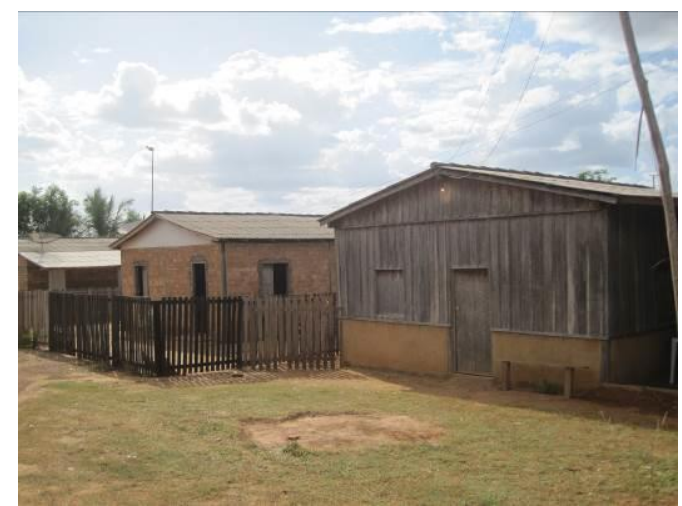

Fonte: SOUZA, Felipe Melo, 2013

\section{CONSIDERAÇÕES FINAIS}

O município de Alto Alegre possui um traçado urbanístico muito bem organizado, com quadras no formato quadrado, criando uma unidade em relação ao seu conjunto, as ruas são bem arborizadas, mas já sofrendo alguns problemas decorrentes das raízes da árvore "oiti" que danificam a tubulação de água.

Outra característica é a organização das avenidas, sendo a avenida $1^{\circ}$ de julho, como principal avenida que liga o município a outras localidades e regiões, com as avenidas são em sua grande maioria perpendiculares a avenida $1^{\circ}$ de julho, uma característica tipo espinha de peixe, forma esta também utilizada em alguns municípios como o município de Rorainópolis, que possui uma diferença, tem mais uma avenida secundária, o que distribui melhor a área de valorização e importância do município.

As avenidas perpendiculares possuem poucos comércios, situados em sua grande maioria nos lotes de esquina, uma vez que estão em pontos estratégicos das 


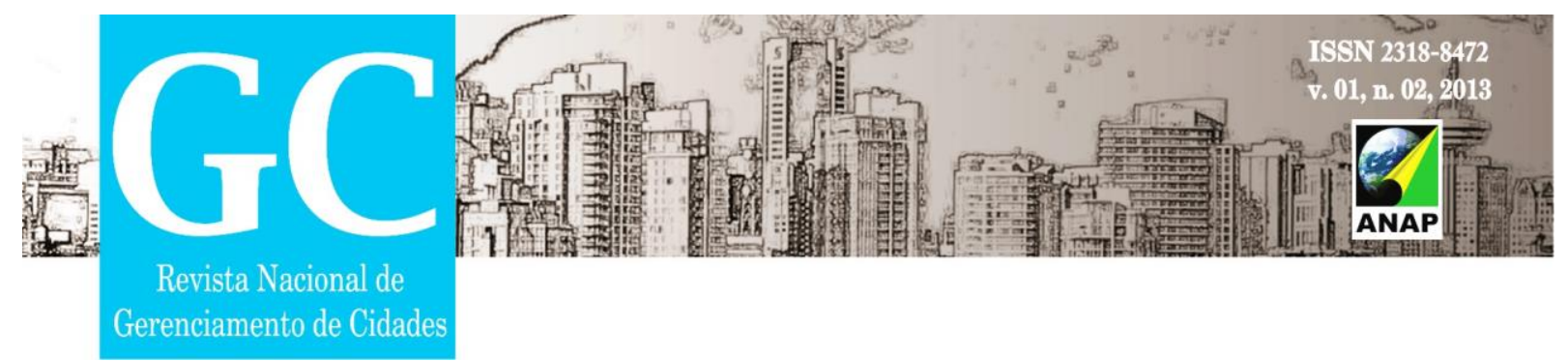

quadras, e as demais são todas habitações, com grandes vazios urbanos, necessitando de políticas de ordenamento urbano como forma de organizar e induzir o desenvolvimento do município.

O bairro conhecido como "azul", possui uma excelente área para a construção de habitações, pois foi incorporada de área rural para urbano, criando uma transformação, que ainda ocorre na paisagem, sendo necessários ainda obras de infraestrutura para a valorização da área, uma vez que o bairro tem ainda muitos vazios urbanos decorrentes do baixo adensamento urbano.

Com isso é necessário que o município pense $\mathrm{o}$ plano diretor e principalmente políticas de desenvolvimento urbano como forma de potencializar as áreas desvalorizadas e criando condições de melhoria da infraestrutura, não se esquecendo de considerar as questões ambientais e a sua sustentabilidade.

Deve ser também objetivo do município, ter um melhor controle e fiscalização nas novas obras, que em alguns casos avançam consideravelmente no logradouro, dificultando a locomoção dos pedestres e alterando a configuração do alinhamento das edificações.

\section{REFERÊNCIAS}

CLAVAL, Paul. Terra dos Homens. Tradução Domitila Madureira. São Paulo. Contexto, 2010.

DEL RIO, Vicente. Introdução ao desenho urbano no processo de planejamento. São Paulo; Pini, 1990

KOZEL, Salete, MENDONÇA, Francisco. Epistemologia da geografia contemporânea. Paraná. Editora UFPR. 


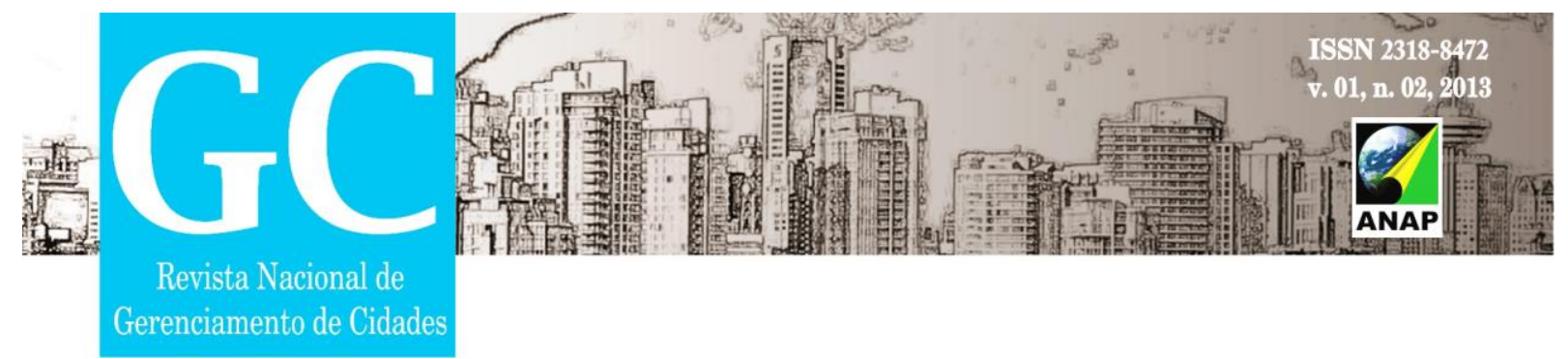

MORIN, Edgar. 1. A natureza da natureza. Tradução llana Heineberg. Porto Alegre: Sulina, 2 ${ }^{\text {a }}$ Edição, 2003.

SANTOS, Boaventura de Sousa. Conhecimento prudente para uma vida decente. São Paulo, Cortez, 2004

SPÓSITO, Eliseu Savério. Geografia e Filosofia, contribuições para o ensino do pensamento geográfico. SãoPaulo, Editora UNESP, 2004.

VERAS, Antônio Tolrino de Resende. A Produção do espaço urbano em Boa Vista - Roraima. São Paulo, 2009. 235p. Dissertação (Doutorado em Geografia Humana). Faculdade de Filosofia, Letras e Ciências Humanas, Programa de PósGraduação em Geografia Humana, Universidade de São Paulo.

VILLAÇA, Flávio. Espaço intra-urbano no Brasil. 2. Ed. São Paulo: Studio Nobel, FAPESP, Lincoln Institute 